EASTERN REVIEW 2016, T. 5

Ирина Орлова

\title{
Модернизационные процессы в российском обществе
}

Прежде всего, процессы модернизации связывают в России с формированием демократического государства. В демократическом обществе власть государства ограничивают, сдерживают и контролируют граждане, которые действуют в рамках гражданского общества, защищающего частные интересы, индивидуальные и групповые. Социально-политические изменения, которые произошли и происходят в России настоятельно требуют активного вовлечения масс в процессы управления и принятия решений. Для формирования демократического государства необходим определенный опыт, традиции, и, конечно же, общественно-политическая активность граждан. Она формируется на основе, как минимум, трех источников.

Первый и главный из них - современная отечественная политическая практика, которая основывается на нормативных актах, неформализованных обычаях и социально-политической практике.

Второй источник - зарубежный опыт, главным образом западный. Сегодня заимствование и освоение европейско-американских „образцов” уже не делается „в слепую”, но в то же время нет и четкого представления, что привьется на нашей евразийской почве, а что нет. Однако, не трудно предположить, что, как бы ни складывались в дальнейшем отношения России с Западом, он и впредь останется для нас источником формирующейся гражданской культуры.

Наконец, третий ее источник - национальная традиция. гражданская культура любого общества, тем более обладающего многовековыми устойчивыми традициями, развивается на основе преемственности. Для России всегда было характерна централизация политического руководства и административного управления. Эта тенденция внутренне присуща любому политическому режиму (в том числе демократическому), 
складывающемуся на территории столь огромной, этнически, географически и культурно разнородной страны, как Россия. Необходимость сохранения целостности российского государства и общества подталкивает к того, что государственные органы власти наделяются большими полномочиями как в управлении, так и в контроле за общественными процессами. Такой партикуляризм находит отражение в политико-культурных ориентациях россиян. Вопрос, следовательно, состоит в том, чтобы сформировать у россиян контрэтатистскую установку, но направленную не на разрушение государства как политического института (антиэтатизм), а на ограничение его экспансионистских поползновений, на избавление людей от патерналистских упований и способствующую развитию их способности к саморегулированию и самоорганизации.

Общественный контроль является важным средством обеспечения законности и демократии в общественном развитии, повышения эффективности деятельности органов государственной власти и органов местного самоуправления, снижения рисков принятия и реализации противоправных и (или) противоречащих общественным интересам решений, механизмом обеспечения социальной и политической стабильности в обществе, более полной реализации конституционных прав граждан на участие в управлении делами государства.

Развитие институтов общественного контроля указывается в числе главных мер по профилактике коррупции ${ }^{1}$. В условиях отсутствия общественного контроля, роль административного усмотрения чиновников возрастает до уровня вседозволенности, что для развитого гражданского общества является недопустимым.

Анализ существующей практики общественного контроля в Российской Федерации свидетельствует, что целостная система общественного контроля в стране отсутствует, а эффективность проводимых мероприятий в большинстве случаев крайне невелика и не приводит к существенному улучшению качества государственного управления, местного самоуправления, что ведет к росту коррупции, неудовлетворенности граждан, нарастанию социального напряжения в обществе. Причин сложившейся ситуации несколько.

Одна из главных проблем состоит в том, что существующее правовое регулирование общественного контроля в Российской Федерации фрагментарно и поверхностно. В действующем законодательстве отсутствует определение общественного контроля, не указаны его основные формы и методы, в большинстве случаев, отсутствуют конкретные механизмы его реализации. Законодатель часто ограничивается исключительно констатацией

${ }^{1}$ Ст. 6, 7 Федерального закона от 25 декабря 2008г., № 273-Ф3 „, О противодействии коррупщии” (в ред. Ф3 от 21.11.2011 No. 329-Ф3), „Собр. законодательства Российской Федерации" 2008, № 52, Ч. 1, с. 6228. 
общественного контроля, а имеющиеся в отдельных законах и нормативных правовых актах более развернутые формулировки, никак не объясняют сути и, главное, порядка осуществления общественного контроля. Другими словами, существующий уровень правового регулирования не способствует тому, чтобы деятельность отдельных субъектов и институтов общественного контроля сложилась в целостную систему.

Вторая большая проблема - низкая вовлеченность широких масс населения и институтов гражданского общества в лице реальных общественных организаций в осуществление общественного контроля за деятельностью государственных органов власти и местного самоуправления. Во многом это связано с низким уровнем доверия населения к самим институтам гражданского общества.

Так, если число россиян согласных с утверждением, „что людям можно доверять" с 2009 по 2014 год увеличились с 27\% до 34\%. Остальные склоняются к мысли, что в отношениях с людьми следует быть осторожными ${ }^{2}$. Для сравнения - уровень доверия граждан в Дании $-67 \%$, Норвегии $-62 \%$, Финляндии $-58 \%$, в Швеции $-56 \%$ ). Выше уровень доверия также в Нидерландах (48\%), Швейцарии $(42 \%)^{3}$. В то же время доверие к институтам гражданского общества среди россиян остается весьма не высоким, всего $8 \%$ населения готовы обратится за помощью в решением своих проблем к общественным организациям ${ }^{4}$. Поэтому, насущным остается создание общественных структур, которые вызовут доверие и уважение со стороны общества и государства. Учитывая российский менталитет и особенности межсекторных отношений, наша страна пошла по пути легитимации общественного контроля.

В зарубежной практике понятие общественного контроля, как правило, не прописывается юридически, его отдельные компоненты закреплены за разными государственными органами власти или институтами гражданского общества. По отдельным направлениям общественный контроль осуществляют парламенты, судебная власть, общественные фонды, некоммерческие организации, группы граждан ${ }^{5}$. Вследствие этого отсутствует и единый закон регулирующий институт общественного контроля в целом. Как правило, под общественным контролем понимается контроль со стороны общественных организаций или других институтов гражданского

2 Общественное мнение - 2014, Левада-Центр, Москва 2015.

3 Л. Бзегежева, Проблемы и перспективы развития системы общественного контроля в Российской Федерации, „Вестник Майкопского государственного технологического университета" 2016, nо. 1, http://www.asi.org.ru/ASI3/rws_asi.nsf/va_WebResources/povysh/ \$File/povysh.pdf (30.11.2016).

${ }^{4}$ Общественное мнение...

5 Федеральный закон от 21.07.2014, № 212-ФЗ „,Об основах общественного контроля”. 
общества за деятельностью органов государственной и муниципальной власти. В целом, можно выделить следующие общепринятые формы: публичные, экспертные, негосударственные и формы прямого участия.

К публичным формам обычно относят общественные консультации (слушания), отзывы, общественные расследования, деятельность специальных органов. К экспертным формам причисляют общественный аудит, социальный аудит, антикоррупционный аудит, экспертизу, научные исследования. Негосударственные формы включает деятельность общественных и коммерческих организаций, а формы прямого участия привлекают непосредственно граждан к оценке и аудиту.

В качестве публичной формы общественного контроля в зарубежных странах (в особенности в странах с англо-саксонской правовой системой) популярны общественные консультации. Общественные консультации могут осуществляться в различных формах.

Bo-первых, применяются т.п. общественные отзывы (notice-and-comment). В рамках этой процедуры инициативы органов власти публикуются, а затем все заинтересованные стороны в письменной форме высказывают свои мнения. В Японии публичным отзывам подлежат все регулирующие нормы (и поправки к ним). В США процедура строго прописана законом (Закон об административной процедуре), все комментарий заинтересованных групп официально фиксируются. При этом авторы инициатив могут отвергнуть ряд комментариев, но в случае если эти комментарии поступили от множества граждан, это решение может быть оспорено в суде. В Дании подобная процедура применяется в основном во время принятия решений на низовых уровнях власти и при этом формально не прописана.

Во-вторых, популярной формой являются общественные слушания ( $p u b$ lic hearing), при которых происходит открытая встреча заинтересованных в принятии инициативы или ее последствий лиц. Так, в США общественные слушания на прямую связаны с процедурой отзывов и следуют сразу за последними. В Финляндии общественные слушания проходят либо совместно с отзывами или замещают их.

В-третьих, в ряде стран общественные консультации осуществляются специальными органами - общественными советами (advisory bodies). В функции этих органов входит консультирование органов власти относительно различных инициатив.

Так, например, Экономический, социальный и экологический совет во Франции, согласно первой статье Органического Закона от 2010 года, регулирующего деятельность этого органа, в частности, занимается рассмотрением вопросов, касающихся экономической, социальной и экологической сфер, а также анализом соответствующих направлений государственной политики и предлагает рекомендации, которые считает необходимым, однако его деятельность носит лишь консультативный характер. 
Совет по экономическому и социальному развитию Бразилии, согласно регулирующему его деятельность закону от 2003 года, в том числе занимается экспертизой государственной политики, предложений по реформе экономической и социальной сфер. Таким образом, помимо функций органа, связующего общество и правительство Совет имеет функции общественного контроля.

Другой пример подобного органа - Экономический и социальный совет Португалии, основные функции которого указаны в Конституции Португалии (ст. 92). Совет участвует в разработке предложений об основных направлениях экономического развития, но при этом является консультативным органом. Однако, Правительство обязано запрашивать Совет о составлении отчета хотя бы один раз в год.

Помимо общественных консультаций, еще одной эффективной формой общественного контроля являются общественные расследования (public inquiries). Институт общественных расследований действует в ряде стран англо-саксонской правовой системы в Австралии, Великобритании, Ирландии, Канаде. Особенностью общественного расследования является то, что все доказательства и материалы рассматриваемого дела становятся известны широкой общественности, и при этом заинтересованные представители общественности могут не только сделать собственные письменные заявления, но и выслушать устные показания, данные другими сторонами процесса. Обычно в формате общественного расследования рассматриваются резонансные дела (зачастую связанные с большим количеством человеческих жертв - массовые убийства, крупные аварии). При этом оппозиционные партии зачастую требуют проведения общественного расследования по большому количеству поводов, их запросы отклоняются, т.к. проведение таких расследований требует больше времени и затрат. Результаты общественного расследования представляются в письменной форме в первую очередь правительству, а затем публикуются для широкой общественности. В частности, эти результаты обычно содержат рекомендации по совершенствованию механизмов управления государственных учреждений и работы органов власти.

Публичные расследования возглавляет известный уважаемый человек (известный юрист, профессор, или высокопоставленный служащий), который назначается правительством с предоставлением специального ордера на проведение расследования в установленные сроки.

При этом публичные расследования могут проводится без поручения правительстве - в таком случае имеет место неправительственное расследование (citizens inquiry).

В Ирландии в качестве одного из институтов антикоррупционной деятельности предусмотрены независимые трибуналы (общественные комиссии по расследованию были закреплены Законом о трибуналах еще 
в 1921 году), которые формируются из авторитетных судей и юристов и занимаются расследованием конкретных фактов коррупции - дел общественной значимости. Трибуналы часто действуют по поручению Парламента Ирландии. В качестве примера можно привести наиболее длительное и резонансное дело Mahon Tribunal, которое продолжалось с 1997 по 2012 год и касалось политической коррупции.

В ряде стран (например, Швеция, Ирландия) некоторые функции по осуществлению общественного контроля над органами государственной власти берет на себя омбудсмен.

Некоммерческие организации в различных формах также берут на себя функции негосударственного контроля в области противодействия коррупции (в некоторых странах это прежде всего отделения Transparency International, так же существуют крупные локальные организации, такие как гражданская ассоциация „Прозрачность и честность” в Португалии, антикоррупционная ассоциация „Антикор” во Франции, множество неправительственных организаций в США - Judicial Watch, Global Integrity и др.

Экспертная форма общественного контроля осуществляется обычно учеными и исследователями по заказу общественных организаций или органов власти.

Одной из форм общественного контроля этого типа является социальный аудит (social audit) - оценка общественной ценности, создаваемой теми или иными организациями. Социальный аудит может осуществляться как по заказу органов власти так и по заказу коммерческих или некоммерческих организаций.

В Великобритании действует негосударственное сообщество социального аудита - общественное объединение, собирающее информацию об организациях занимающихся социальным аудитом и о результатах их исследований. В Шотландии аналогичное объединение носит название Social Impact Scotland.

В Швеции предусмотрен особый порядок проведения социального аудита: общественный контроль осуществляется группой экспертов (4-5 человек). Доклады по социальному аудиту посвящены эффективности государственного управления, участию граждан в политике, развитию политических партий.

В отличие от социального аудита, общественный аудит (public audit) предполагает общественный контроль не над уровнем общественной полезности, а над расходованием денег, соответствующим общественным интересам. В Австралии общественный аудит осуществляется специальной Объединенной комиссией по контролю над расходованием государственных средств. Комиссия занимается проверкой государственной власти на предмет законности, эффективности и результативности. В Чехии общественным аудитом занимается специальное Высшее агентство по контро- 
лю, назначенное президентом республики с согласия парламента и занимается бюджетным контролем всех органов государственной власти. А так же оценкой их финансовой эффективности. В Нидерландах общественным аудитом занимается специальная парламентская Общественная палата по аудиту. При этом Общественный аудит предполагает не столько антикоррупционный анализ, сколько анализ эффективности и результативности с точки зрения общественного интереса.

В качестве яркого примера негосударственной формы участия в общественном контроле можно привести юридическое оформление в законодательстве Великобритании понятия „компании общественного интереса" (community interest company, CIC), т.е. организации, деятельность которых затрагивает общественные интересы. Компании общественного интереса не могут быть благотворительными или коммерческими, содержание их деятельности скорее всего приближается к понятию „социального предпринимательства”.

В Европейском союзе также развиты формы прямого участия в общественном контроле граждан. Одной из площадок такого общественного контроля является ресурс Your Voice in Europe. Он позволяет в режиме онлайн обсуждать законопроекты, представлять точки зрения на те или иные инициативы, а так еж оставить отзыв о том, как исполняются законы. Другая европейская площадка Solvit посвящена сбору жалоб на неправильное применения законов.

В Италии действует система „Электронный сход граждан”. Она позволяет в Интернете комментировать те или иные инициативы местной власти. Комментарии таких дискуссий собираются и формулируются в предложения по изменению инициатив.

В Великобритании сервис They Work For You позволяет отследить работу каждого депутата от округа: его голосование, высказывания в дебатах, а затем сформировать о нем свое мнение и решить голосовать за него на следующих выборах или нет.

В России настоящее время общественный контроль в большинстве случаев реализуется через обращения граждан (общественных объединений) об известных им нарушениях законодательства. Однако процедура получения таких сведений и обеспечение ответной реакции органов власти в виде принятия конкретных решений, нормами права практически не регулируется. По действующим правилам вся помощь сводится к предоставлению информации, что регламентировано Федеральным законом „О порядке рассмотрения обращений граждан Российской Федерации”“ и Федеральным законом

6 Федеральный закон от 2 мая 2006 г., №. 59-Ф3 „,О порядке рассмотрения обращений граждан Российской Федераичи” (в ред. ФЗ от 02.07.2013), „Российская газета”, 05.05.2006. 
„Об обеспечении доступа к информации о деятельности государственных органов и органов местного самоуправления"7.

Механизмы институализированного гражданского участия в общественном контроле представлены довольно широко на федеральном уровне и на уровне субъектов федерации: общественные палаты, институты уполномоченных по правам человека и по правам детей, молодежные парламенты и т.д. Но как видим, наиболее развиты те формы, которые больше всего связаны с властью, формируется ею, интегрированы во властные структуры.

Относительно новой формой общественного контроля являются общественные советы, учреждаемые при федеральных органах исполнительной власти (далее - ФОИВ). Причем, нынешняя компетенция советов укладывается все так же в сферу регулирования законов об обращениях и порядке информирования о деятельности органов государственной власти. В то же время, по данным социологов, в России „более половины опрошенных представителей НКО считает: в деятельности общественно-консультативных советов участвуют »карманные« НКО либо НКО, отобранные по неясному принципу”. Так называемые, псевдо-НКО или GONGO (governmentally oriented или governmentally organized non-governmental organizations), т.е. псевдонеправительственные организации.

Успешная международная практика общественного контроля (например, в скандинавских странах) свидетельствует, что контролером государства должно выступать все общество в лице его разнообразных разветвленных институтов: общенациональных и созданных по месту жительства, профсоюзных и предпринимательских, потребительских и правозащитных, молодежных и ветеранских, конфессиональных и секулярных. Однако, для этого нужно, чтобы каждый типичный гражданин не просто формально принадлежал к этим структурам, изредка вспоминая об их существовании, как это зачастую имеет место у нас, а повседневно и активно участвовал в их работе. Сами же эти разнообразные структуры должны тесно сотрудничать между собой, образуя плотную сеть.

Соединяя успешный зарубежный и отечественного опыт, и стремясь создать целостную систему эффективного общественного контроля, в Российской Федерации принят закон „Обосновах общественного контроля”. Эффективный общественный контроль, как планируется, должен повысить качество принимаемых законов и иных нормативно-правовых актов, а также ответственность лиц, принимающих их, что в конечном итоге позитивно

7 Федеральный закон от 9 февраля 2009, № 8-Ф3 „Об обеспечении доступа к информации о деятельности государственных органов и органов местного самоуправления" (в ред. Ф3 от 11.07.2011, № 200-Ф3), „Собрание законодательства Российской Федерации” 2009, № 7 , c. 776. 
отразится на процессе обеспечения единого правового пространства Российской Федерации, дальнейшей демократизации государства.

Общественный контроль - системная деятельность, осуществляемая в общественных интересах негосударственными субъектами (институтами гражданского общества и отдельными гражданами), направленная на выявление и устранение нарушений правовых норм органами государственной власти и местного самоуправления, а также их должностными лицами.

Общественные интересы - осознаваемые обществом потребности в обеспечении безопасности и благополучии, стабильности и устойчивом развитии, реализации конституционных прав и свобод граждан.

Основные принципы общественного контроля:

1) независимость - самостоятельность субъектов общественного контроля и их независимость от органов государственной власти и местного самоуправления;

2) вовлеченность - участие граждан и институтов гражданского общества в общественном контроле на общих основаниях; возможность участия в общественном контроле должна быть гарантирована в равной степени любому гражданину, желающему защищать общественные интересы;

3) всеохватность - общественный контроль должен распространяться не только на органы государственной власти и местного самоуправления, но и на негосударственные учреждения, использующие бюджетные средства или налоговые льготы;

4) открытость - абсолютная информационная открытость, прозрачность и гласность деятельности по осуществлению общественного контроля, включая рассмотрение результатов;

5) обязательность - обязательность для органов государственной власти и местного самоуправления (объектов контроля) вынесения мотивированного заключения по результатам общественного контроля; невозможность уклониться от общественного контроля (за исключением особых случаев, установленных федеральным законодательством).

Главные цели совершенствования общественного контроля в Российской Федерации:

1. Повышение эффективности деятельности органов государственной власти и органов местного самоуправления.

2. Обеспечение законности в сфере государственного управления, снижение рисков принятия и реализации противоправных и (или) противоречащих общественным интересам решений.

3. Обеспечение социальной и политической стабильности в обществе, более полной реализации конституционных прав граждан на участие в управлении делами государства. 
Для достижения поставленных целей, необходимо решить следующие задачи:

- создание стройной законодательной базы обеспечения общественного контроля в Российской Федерации;

- создание информационно-аналитической и методической базы для развития гражданского общества через возможности общественного контроля;

- создание организационных основ для формирования целостной системы общественного контроля, охватывающей все сферы и направления деятельности органов государственной власти и местного самоуправления;

- расширение гарантий конституционного права граждан на участие в управлении делами государства на всех уровнях - федеральном, региональном и муниципальном;

- повышение прозрачности и подотчетности деятельности органов государственной власти и местного самоуправления;

- ликвидация излишних государственных функций, включая отдельные контрольно-надзорные;

- обеспечение роста гражданской активности населения;

- стимулирование и координации инициатив профессиональных сообществ, направленных на защиту и отстаивание общественных интересов;

- повышение доверия населения к органам власти;

- повышение доверия к НКО как со стороны власти, так и со стороны гражданского общества и граждан;

- формирование институтов электронной демократии (e-democracy), включая т.н. „облачную демократию” (использование информационных технологий для расширения возможностей каждого гражданина);

- замена политических, командно-административных взаимоотношений государства и общества на договорные, мотивационные, социальные.

Основные формы общественного контроля (перечень не является исчерпывающим и может быть дополнен иными формами, не противоречащими законодательству Российской Федерации):

1) общественная экспертиза - форма общественного контроля, основанная на использовании субъектами общественного контроля специальных знаний и (или) опыта для исследования, анализа и оценки документов и материалов, касающихся деятельности объектов общественного контроля, на предмет их соответствия общественным интересам;

2) общественный мониторинг (аудит) - форма общественного контроля, представляющая собой постоянное, систематическое наблюдение со стороны субъектов общественного контроля за соответствием общественным интересам деятельности объектов общественного контроля;

3) общественные слушания (обсуждение) - форма общественного контроля, заключающаяся в реализации прав граждан на участие в процессе принятия решений органами государственной 
власти, органами местного самоуправления посредством проведения собрания для публичного обсуждения проектов указанных решений с обязательным участием уполномоченных лиц органов власти и органов местного самоуправления, представителей граждан, интересы которых непосредственно затрагиваются соответствующим решением, а также действующих нормативных правовых актов по вопросу их соответствия общественным интересам:

4) общественная проверка (расследование) - форма общественного контроля, представляющая собой совокупность действий субъектов общественного контроля по сбору информации, установлению фактов и обстоятельств, касающихся деятельности объектов общественного контроля в целях определения ее соответствия общественным интересам;

5) общественный (наблюдательный, консультативный, экспертный) совет - форма общественного контроля, основанная на участии субъектов общественного контроля в деятельности коллегиальных органов, специально созданных объектами контроля.

В условиях отсутствия единой универсальной классификации методов общественного контроля, которая в принципе невозможна, так как ее наличие означало бы - поставить богатую, многостороннюю деятельность в рамки жестких логических схем, Концепция выделяет следующие основные методы общественного контроля:

1) методы стимулирования и мотивации (дискуссия, эмоциональное воздействие, убеждение, порицание и осуждение, поощрение) - основаны на особых способах правового воздействия в системе общественного контроля, которые заключаются в использовании субъектом контроля общепризнанных моральных, этических и ценностных установок, ведут в итоге не только к формированию у объекта общественного контроля (должностного лица органа государственной власти или местного самоуправления) дисциплинированности, понимания того, что общественная дисциплина и законность представляют собой необходимые условия для успешного построения демократического государства, формированию сознательной привычки, направленной на соблюдение правовых требований, чувства недопустимости их нарушения, но и способствуют устранению выявленных нарушений (например, обнародование фактов злоупотребления властью, нарушений законности в системе государственного управления с целью придать их широкой огласке и формированию негативного отношения масс населения к лицам, их совершившим, может вызвать не только негативный резонанс в обществе, но и стать поводом для расследования официальными государственными структурами);

2) ситуативные методы (наблюдение, эксперимент, экспертиза, групповые дискуссии, анализ случаев (,кейс-метод”), краудсорсинг, мозговой штурм) - основаны на наблюдении субъекта общественного контроля за 
объектом контроля в реальных или инсценированных (симулированных) ситуациях, с последующим анализом на предмет соответствия действий объекта правовым установкам;

3) репродуктивные методы (мониторинг, рейтингование, проверка) - основаны на особых способах повторяющегося правового воздействия в системе общественного контроля, которые заключаются в использовании субъектом контроля определенного алгоритма, т.е. специально разработанных правил и порядка действий, в результате выполнения которых выясняется наличие или отсутствие нарушений в деятельности объекта контроля.

На сегодняшний день выделяют три основных направления совершенствования форм и методов общественного контроля в Российской Федерации на период 2013-2018 гг.:

1) Создание организационных и правовых основ общественного контроля в Российской Федерации посредством законодательного и нормативного правового регулирования.

2) Внедрение и развитие механизмов открытости органов государственной власти и местного самоуправления.

3) Создание условий (стимулирование) для вовлеченности широких масс населения и институтов гражданского общества в лице реальных НКО в осуществление общественного контроля за деятельностью государственных органов власти и местного самоуправления.

Приоритетные направления внедрения и развития механизмов открытости органов государственной власти и местного самоуправления:

- работа с открытыми данными: повышение качества, полноты, достоверности и актуальности предоставляемой информации;

- совершенствование работы общественных (экспертных, консультативных, координационных и др.) советов, комиссий, рабочих групп: обеспечение вовлечения в широкое обсуждение как можно большего количества граждан, представителей различных социальных групп, институтов гражданского общества;

- совершенствование форм и способов обратной связи с гражданами, в т.ч. процедур онлайн-взаимодействия на официальных сайтах органов власти, различных ведомств.

Одной из центральных идей совершенствования общественного контроля в Российской Федерации, которая будет способствовать вовлеченности широких масс населения в эту деятельность - является создание специального электронного ресурсного центра (единого Интернет-портала) общественного контроля, способного функционировать по принципу „одного окна”.

Стремление власти привлечь население через конструктивное взаимодействие к вопросам осуществления общественного контроля должно найти поддержку общества. Со своей стороны общественные 
организации могут создать систему общественных связей для участия в контроле за деятельностью органов публичной власти, разработать методики осуществления общественного контроля, обобщив зарубежный опыт, развивать международное сотрудничество в сфере общественного контроля.

Защитить свои права и интересы население может только в том случае, если будет принимать активное участие в разработке нормативных правовых актов, формировании различных социальных программ и планов развития общества и тем самым способствовать развитию демократической практики среди россиян.

\section{Библиография}

Бзегежева Л., Проблемы и перспективы развития системы общественного контроля в Российской Федераиии, „Вестник Майкопского государственного технологического университета" 2016, № 1, http://www.asi.org.ru/ASI3/rws_asi. nsf/va_WebResources/povysh/\$File/povysh.pdf (30.11.2016).

Общественное мнение - 2014, Левада-Центр, Москва 2015.

Федеральный закон от 2 мая 2006 г., № 59-Ф3 „, О порядке рассмотрения обращений граждан Российской Федераиии” (в ред. ФЗ от 02.07.2013), „Российская газета", 05.05.2006.

Федеральный закон от 21.07.2014, № 212-Ф3 „Об основах общественного контроля”, „Российская газета”, 23.07.2014.

Федеральный закон от 25 декабря 2008г., № 273-Ф3 „О противодействии коррупици” (в ред. Ф3 от 21.11.2011 No. 329-Ф3), „Собрание законодательства Российской Федерации” 2008, № 52, Ч. 1, с. 6228.

Федеральный закон от 9 февраля 2009, № 8-Ф3 „Об обеспечении доступа $\kappa$ информации о деятельности государственных органов и органов местного самоуправления” (в ред. Ф3 от 11.07.2011, № 200-Ф3), „Собрание законодательства Российской Федерации" 2009, № 7. 


\section{Irina Orłowa}

\section{Procesy modernizacyjne w obrębie rosyjskiego społeczeństwa}

W artykule podnoszony jest problem demokratyzacji rosyjskiego społeczeństwa, ze szczególnym uwzględnieniem instytucjonalnych form kontroli społecznej w Federacji Rosyjskiej. Autorka podkreśla znaczenie przyjęcia ustawy O podstawach kontroli społecznej, z punktu widzenia ochrony i promocji interesów obywateli Rosji. Autorka zwraca szczególną uwagę na rozszerzanie się praw i możliwości obywateli i NGO w procesie zarządzania państwem, zwiększania transparentności działań organów władzy państwowej. Kontrola społeczna nad powinna sprzyjać zwiększaniu efektywności działalności wspomnianych organów władzy państwowej i samorządu terytorialnego. W wyniku wprowadzania mechanizmów kontroli społecznej zmniejsza się ryzyko przyjmowania i realizacji decyzji sprzecznych z interesami społecznymi. Ustawa, o której mowa w artykule, sprzyjać będzie wzrostowi społecznej i politycznej stabilności w społeczeństwie i pełniejszej realizacji konstytucyjnych praw obywateli do udziału w zarządzaniu sprawami państwa.

Słowa kluczowe: modernizacja, Rosja, NGO, społeczeństwo obywatelskie

\section{Irina Orłowa}

\section{Modernization Processes in Russian Society}

This paper discusses the process of institutionalization of social control in the Russian Federation. Proved the importance of the adoption of the federal law „On the basis of social control" to protect and promote the interests of citizens. The author pays special attention the empowerment of citizens and NGOs in managing state affairs, to ensure transparency and openness of public authorities. It is concluded that due to public scrutiny should occur increasing the efficiency of public authorities and local governments. As a result of the introduction of mechanisms of public control should be a decrease in the risk of illegal adoption and implementation, and (or) contrary to the public interest decisions. The law will contribute to social and political stability in the society, a more complete realization of the constitutional rights of citizens to participate in public affairs.

Keywords: modernizations, Russia, NGOs, civil society 